\title{
Preparation of halide sensors by means of co-precipitation of silver sulphide and silver halide
}

\author{
Armila Rajbhandari (Nyachhyon)*, Krishna Manandhar, Raja Ram Pradhananga \\ Central Department of Chemistry, Tribhuvan University, Kirtipur, Kathmandu, Nepal \\ E-mail;armila3@yahoo.com
}

\begin{abstract}
Halide sensors have been prepared in the laboratory by means of co-precipitation of silver sulphide and silver halide and is used for the determination of iodide, bromide and chlorides ions. The iodide sensors show a Nernstian response in the concentration range of $10^{-1}$ to $10^{-6} \mathrm{M}$ iodide ions, bromide sensors show a linear response in the concentration range of $10^{-1}$ to $10^{-5} \mathrm{M}$ bromide ions while chloride sensors show linear response upto the concentration range of $10^{-4} \mathrm{M}$ chloride ions. The response time of all the electrodes, is < Iminute. The iodide sensors were found to be selective towards iodide ions in the presence of $\mathrm{Cl}^{-}$and $\mathrm{Br}^{-}$ions while bromide and chloride sensors interferred by iodide ions as indicated by selectivity coefficient values of 3.98 and 48.9 respectively. These sensors have been successfully applied for potentiometric titrations.
\end{abstract}

Keywords: Halide sensors, Nernstian response, Selectivity coefficient, Potentiometric titrations

\section{Introduction}

Halide sensors are ion selective electrodes (ISEs) that provide a convenient and quick analytical procedure for the estimation of halide ions in the solution. Because of the simplicity, low cost, improved accuracy, applicability to extreme conditions and timeliness, they are recognized as novel analytical tools [1]. Their properties and characteristics make them suitable for diverse fields of analysis such as pharmaceutical analysis, plant and vegetable analysis, seawater analysis. Ion selective electrodes of different types are reported in the literature [1]. Silver sulphide based solid state ion selective electrodes [2-7] are one of the promising electrode as these are free from problem of leakage and evaporation of internal electrolytes. In addition to this, silver sulphide based electrodes have desirable properties like robustness due to solid back contact, low resistivity and high electronic and ionic conductivity. Though the commercial halide sensing electrodes are available in the market, the costs of the electrodes are extremely high and it became unaffordable to purchase for the educational institutions of developing countries like Nepal. In commercial electrodes, details of methods of preparation of electrodes are not given; they are kept as trade secrets. In this study, preparation details of iodide, bromide and chloride ion sensors by optimizing different parameters have been described. The response behavior, response time and selectivity of fabricated electrodes were studied. Potentiometric titrations were performed to evaluate the performances of electrodes.

\section{Experimental}

\section{Reagents and apparatus}

All the reagents silver nitrate, potassium iodide, potassium bromide, potassium chloride were of analytical grade. All the solutions were prepared in distilled water. All potentiometric measurements on

\footnotetext{
${ }^{*}$ Corresponding author
} 
electrodes were performed with OSAW digital potentiometer, India. The silver silver chloride electrode (SSE) was used as a standard reference electrode. All the measurements were carried out in constant stirring conditions at $25^{\circ} \mathrm{C}$.

\section{Fabrication of iodide, bromide and chloride sensors}

\section{Preparation of materials}

The mixed composite of silver sulphide silver halide (Iodide/Bromide/Chloride) polycrystalline materials were prepared by co-precipitation technique. To an equimolar solution of potassium halide and sodium sulphide, an excess amount of silver nitrate solution was added till complete precipitation. A general reaction scheme (1) was given below where $\mathrm{X}$ indicates for the iodide / bromide/chloride.

$$
\mathrm{KX}+\mathrm{Na}_{2} \mathrm{~S}+3 \mathrm{AgNO}_{3} \rightarrow \mathrm{Ag}_{2} \mathrm{~S}+\mathrm{AgX}+2 \mathrm{NaNO}_{3}+\mathrm{KNO}_{3} \quad[\mathrm{X}=\mathrm{I} / \mathrm{Br} / \mathrm{Cl}] \ldots \ldots \ldots . .(1)
$$

The materials of composition $\mathrm{Ag}_{2} \mathrm{~S}-\mathrm{AgI}, \mathrm{Ag}_{2} \mathrm{~S}-\mathrm{AgBr}, \mathrm{Ag}_{2} \mathrm{~S}-\mathrm{AgCl}$ were obtained separately. The materials obtained were washed with distilled water and finally with acetone. The material was then allowed to dry in an oven. When it is completely dried, it was grinded into fine powder in an agate mortar. A mesh size was controlled by using sieve size of 106 micrometer.

\section{Preparation of pellet}

The above mentioned fine powdered materials were warmed for 5 minutes at $105^{\circ} \mathrm{C}$ and transferred to $\mathrm{KBr}$ pellet making machine and carefully pressed for 15 minutes by applying 10 tonnes of pressure. Then pellet was carefully taken out from pellet making machine and allowed to sinter for 1 hour at $200^{\circ} \mathrm{C}$. Thus the pellet of composition $\mathrm{Ag}_{2} \mathrm{~S}-\mathrm{AgI}, \mathrm{Ag}_{2} \mathrm{~S}-\mathrm{AgBr}$ and $\mathrm{Ag}_{2} \mathrm{~S}-\mathrm{AgCl}$ having diameter of $12 \mathrm{~mm}$ and thickness of $1.5 \mathrm{~mm}$ were prepared. Then, one side of the pellet was painted with silver paint.

\section{Preparation of sensor body}

The polypropylene tube having a size of $10 \mathrm{~cm}$ length and $12 \mathrm{~mm}$ diameter was taken. The tube was shaped such a way that the pellet could be fitted in one end of the tube while the center of the tube was so managed that a $\mathrm{Cu}$ - wire can be inserted.

A pellet was fitted at one end of the tube using araldite. A silver disk having a copper wire was used as back contact. The wire is about $40 \mathrm{~cm}$ long. The sensor is then abraded using silicon carbide paper from 1000-2000 grit size. The sensor was washed thoroughly with distilled water and then sonicated in water for 15 minutes. Thus sensors of iodide, bromide, chloride were fabricated. The sensors were then preconditioned by immersing it into a solution of respective ions for 30 minutes before use.

\section{Response characterization of sensors}

Two electrode system has been used in this process. Halide sensor was used as an indicator electrode which was coupled with saturated $\mathrm{Ag} / \mathrm{AgCl}$ reference electrode with $\mathrm{NH}_{4} \mathrm{NO}_{3}$ salt bridge. The cell configuration is as follows:

$$
\mathrm{Ag} / \mathrm{AgCl}, \mathrm{KCl} \text { (sat) // sample solution/ halide-ISE / Ag. }
$$

EMF of the cell was measured by varying concentration of primary ion $(\mathrm{I} / \mathrm{Br} / \mathrm{Cl})$ from $10^{-1} \mathrm{M}$ to $10^{-7}$ $\mathrm{M}$ by standard addition technique and ionic strength of the solution was kept $(0.1 \mathrm{M})$ by adding appropriate volume of $1 \mathrm{M} \mathrm{KNO}_{3}$ solution. The measurements were done in constant stirring condition using magnetic stirrer. The potential was recorded after having the stable EMF.

\section{Results and Discussion}

Potentiometric response of iodide sensor

The potentiometric response behavior of iodide sensor to iodide ion was investigated by measuring the cell potential (EMF) at $25^{\circ} \mathrm{C}$ in which the electrode was coupled with a saturated silver-silver chloride 
reference electrode. The ionic strength was maintained to $0.1 \mathrm{M}$ using $1 \mathrm{M} \mathrm{KNO}_{3}$ solution. The result is shown in Fig 1.

The plot showed a linear decrease in EMF in the range of $10^{-1}$ to $10^{-7} \mathrm{M}$ iodide ion concentration. From the best fit in the linear region, the slope was calculated to be $58.7 \mathrm{mV}$ indicating the Nernstian behavior of electrode.

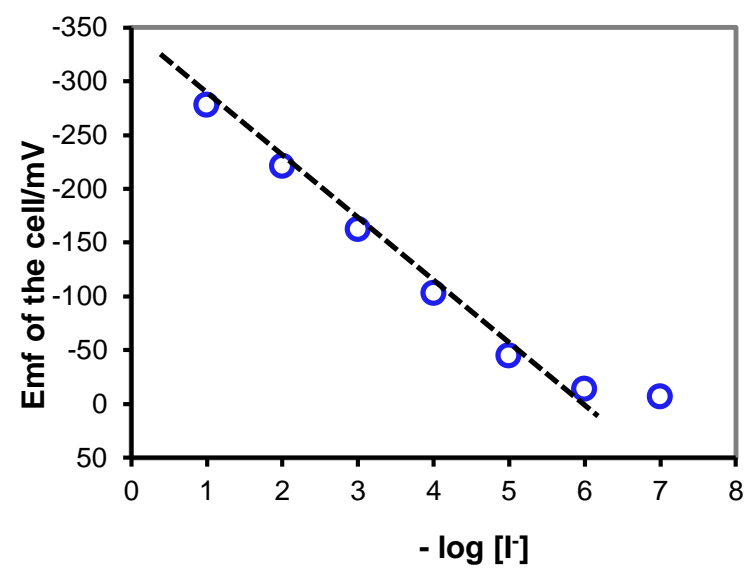

Figure 1: Plot of the cell EMF against-log[I]. Symbols are the data point and dotted line represents the line of best fit.

The time response of electrode was measured in a concentration range of $10^{-1}$ to $10^{-7} \mathrm{M}$ at an interval of 1 second. Fig. 2 shows the time response curve. The stable potential was obtained within 10 seconds.

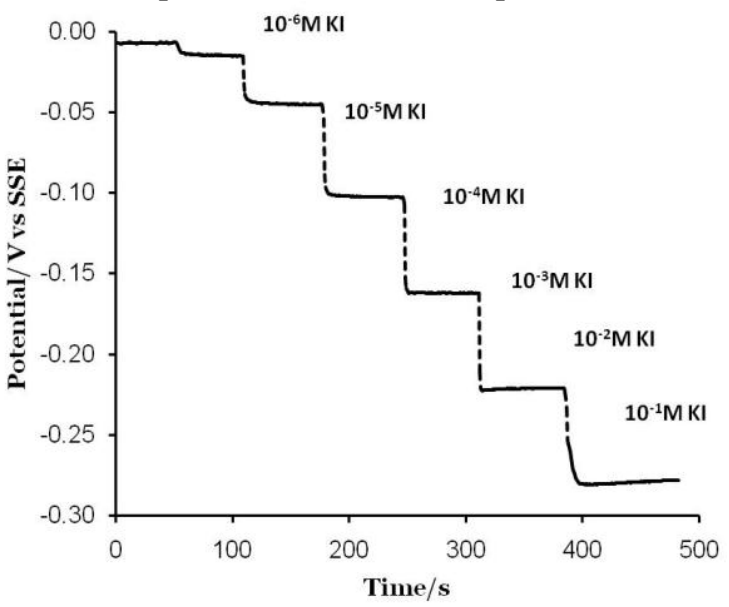

Figure 2: Time response curve of iodide sensor

\section{Potentiometric response of bromide sensors}

Bromide sensor was coupled with silver-silver chloride reference electrode. Then the cell potential was measured to evaluate the response behavior of electrode. The result is shown in Fig 3. A linear response with $58 \mathrm{mV}$ per concentration decade was obtained in the concentration range from $10^{-1} \mathrm{M}$ to $10^{-}$ ${ }^{5} \mathrm{M}$, followed by a non linear region at lower concentrations (Fig.3). 


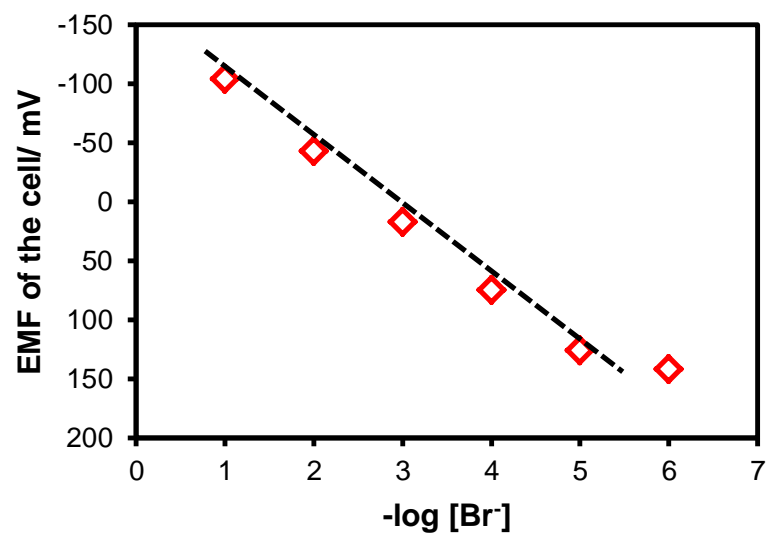

Figure 3: Plot of the cell EMF against - log [Br- ${ }^{-}$. Symbols are the data point and dotted line represents the line of best fit.

The time response curve was obtained which showed fast reponse as in case of iodide sensor.

\section{Potentiometric response of chloride sensors}

The EMF of the cell in $\mathrm{mV}$ with chloride sensor coupled with a saturated silver-silver chloride reference electrode is plotted against $-\log \left[\mathrm{Cl}^{-}\right]$which is shown in Fig. 4.

There is a gradual decay in a linear chloride ion concentration range from $10^{-1} \mathrm{M}$ to $10^{-4} \mathrm{M}$. From the best fit in the linear region, the slope was calculated to be $56 \mathrm{mV}$ indicating the Nernstian behavior of sensor. The linearity deviates at lower concentration.

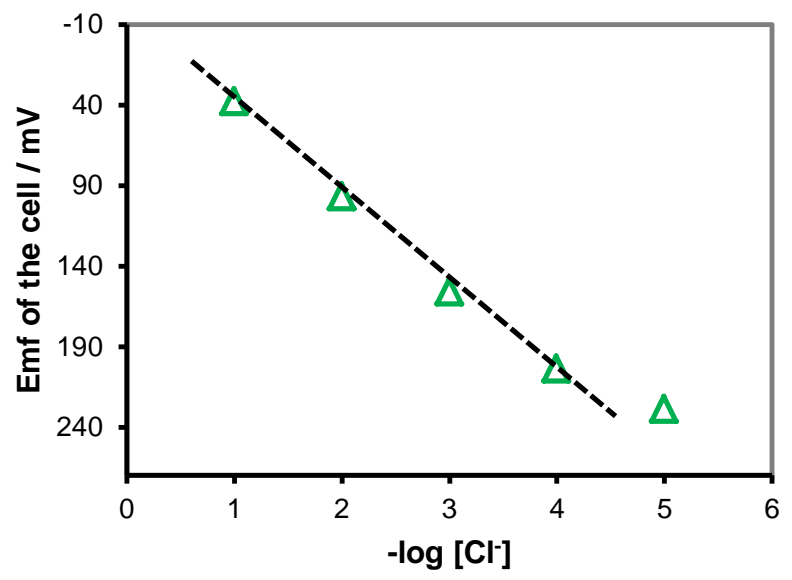

Figure 4: Plot of the cell EMF against - log [Cl]. Symbols are the data point and dotted line represents the line of best fit.

The chloride sensors response very quickly within 30 seconds. 


\section{Potentiometric Selectivity coefficient}

The potentiometric selectivity coefficient indicates the extent to which a foreign ion B interferes with the response of the electrode to its primary ion A. The potentiometric selectivity coefficients $K_{A, B}^{p o t}$ for the suggested sensors were measured by fixed solution method [8]. The value of $K^{p o t}{ }_{A, B}$ is defined by the modified Nickolsky-Eisenman equation (Eq. 2)[8]. The smaller the value of $K_{A, B}^{p o t}$ the greater preference for the principal ion, A.

$$
\mathrm{E}=\mathrm{E}^{0}+\left(\mathrm{RT} / \mathrm{n}_{\mathrm{A}} \mathrm{F}\right) \ln \left(\mathrm{a}_{\mathrm{A}}+\sum \mathrm{K}^{\mathrm{pot}}{ }_{\mathrm{A}, \mathrm{B}}\left(\mathrm{a}_{\mathrm{B}}\right){ }_{\mathrm{A}}^{\mathrm{n}} /{ }_{\mathrm{B}}^{\mathrm{n}}\right)
$$

Where $a_{A}$ and $a_{B}$ are the activities of main and interfering ions having charges $n_{A}$ and $n_{B}$ respectively, $\mathrm{E}^{0}$ is standard potential of the sensor and $K_{A, B}^{p o t}$ is the selectivity coefficient which describes the relative sensitivity of determinant ion. In the present study, fixed solution method [8] was used to determine the selectivity of $\mathrm{Ag}_{2} \mathrm{~S}-\mathrm{AgI}$ sensor containing iodide ion with $\mathrm{Br}^{-}, \mathrm{Cl}^{-}$ions as interfering ions. In this method, the potential of cell comprising an ion sensor and reference electrode is measured with solutions of constant level of interference ions, $\left(\mathrm{Br}^{-}, \mathrm{Cl}^{-}\right)$and varying activity of primary ion $\left(\mathrm{I}^{-}\right)$. Similarly selectivity of $\mathrm{Ag}_{2} \mathrm{~S}-\mathrm{AgBr}$ sensor towards I'and $\mathrm{Cl}^{-}$ions and selectivity of $\mathrm{Ag}_{2} \mathrm{~S}-\mathrm{AgCl}$ sensor towards $\mathrm{I}^{-}$and $\mathrm{Br}^{-}$ions were also studied using fixed solution method. The results obtained are tabulated in Table 1 . These results show that iodide sensors are not affected by bromide and chloride ions where as bromide and chloride sensors are affected by iodide ions.

Table 1: Selectivity Coefficient values of respective electrodes.

\begin{tabular}{|c|c|c|c|}
\hline Electrode & $\begin{array}{c}\text { Primary } \\
\text { ion }\end{array}$ & $\begin{array}{c}\text { Interfering } \\
\text { ion }\end{array}$ & $K_{A, B}^{p o t}$ \\
\hline \multirow{2}{*}{$\mathrm{Ag}_{2} \mathrm{~S}-\mathrm{AgI}$} & \multirow{2}{*}{$\mathrm{I}^{-}$} & $\mathrm{Br}^{-}$ & $7.94 \times 10^{-3}$ \\
\hline & & $\mathrm{Cl}^{-}$ & $1.77 \times 10^{-2}$ \\
\hline \multirow[b]{2}{*}{$\mathrm{Ag}_{2} \mathrm{~S}-\mathrm{AgBr}$} & \multirow{2}{*}{$\mathrm{Br}^{-}$} & $\mathrm{I}^{-}$ & 3.98 \\
\hline & & $\mathrm{Cl}^{-}$ & $8 \times 10^{-2}$ \\
\hline \multirow{2}{*}{$\mathrm{Ag}_{2} \mathrm{~S}-\mathrm{AgCl}$} & \multirow{2}{*}{$\mathrm{Cl}^{-}$} & $\mathrm{I}^{-}$ & 48.9 \\
\hline & & $\mathrm{Br}^{-}$ & 10.0 \\
\hline
\end{tabular}

\section{Potentiometric titration}

To test the usefulness of laboratory prepared iodide, bromide and chloride sensors as an indicator electrode, potentiometric titrations of $\mathrm{KI}$ with $\mathrm{AgNO}_{3}, \mathrm{KBr}$ with $\mathrm{AgNO}_{3}$ and $\mathrm{KCl}$ with $\mathrm{AgNO}_{3}$ were carried out by respective electrodes. A potentiometric titration curve of $1 \times 10^{-2} \mathrm{M}$ potassium iodide with $1 \times 10^{-1} \mathrm{M}$ silver nitrate solution is shown in Fig. 5. Similar titration curves of potassium bromide with silver nitrate and potassium chloride with silver nitrate were observed. A clear inflation point can be observed in the titration curve from which one can conclude that the present electrodes can be utilized as an indicator electrode for respective ions.

\section{Conclusions}

The laboratory fabricated sensors sensitive for iodide, bromide and chloride ions revealed a Nernstian response over a wide concentration range, fast response time. The selectivity coefficient values are as expected. These sensors are found to be applicable as an indicator electrode for respective ions. 


\section{Acknowledgements}

We gratefully acknowledge the support for this work provided by Tribhuvan University, and Nepal Academy of Science and Technology, Nepal.

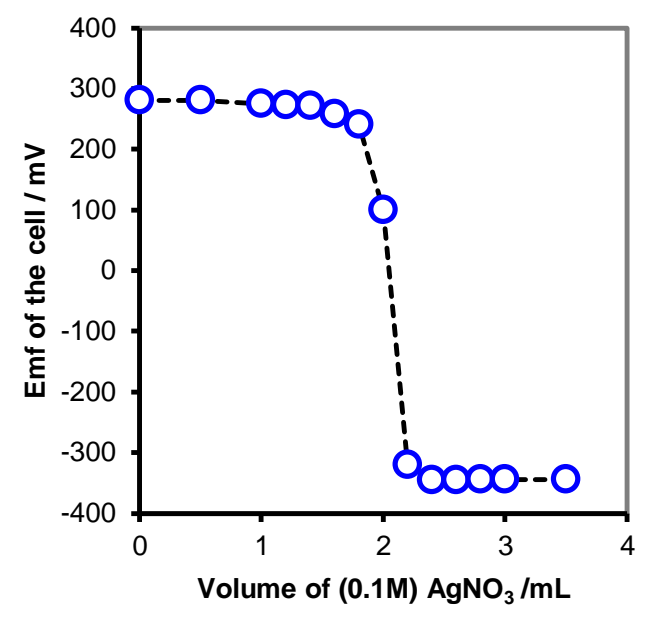

Figure 5: Potentiometric titration $20 \mathrm{~mL}$ of $1 \times 10^{-2} \mathrm{M}$ potassium iodide with $1 \times 10^{-1} \mathrm{M}$ silver nitrate.

\section{References}

1. P.L. Bailey, Analysis with Ion Selective Electrodes, Heyden and Son, London, 1976.

2. R.R. Pradhananga, and L.K, Shrestha, Trans MRS-J, 2008, 33, 345.

3. A. Rajbhandari (Nyachhyon), A.P. Yadav, K. Manandhar and R.R. Pradhananga, Talanta, 2010, 82, 1448.

4. R.R. Pradhananga, A. Rajbhandari (Nyachhyon), Scientific World, 2008, 6, 33.

5. A. Rajbhandari (Nyachhyon), A.P. Yadav, K., Manandhar, R.R. Pradhananga, Scientific World, 2009, 7, 19.

6. A. Rajbhandari (Nyachhyon), A.P. Yadav, K., Manandhar, R.R. Pradhananga, Advanced Materials Research, 2010, 117, 93.

7. A. Rajbhandari (Nyachhyon), A.P. Yadav, K., Manandhar, R.R. Pradhananga, Advanced Materials Research, 2010,117, 7.

8. Y. Umezawa, P. Buhlmann, K. Umezawa, K. Tohda, and S. Amemiya, Pure Appl. Chem. 2000, 72, 1851. 